\title{
ERRATUM
}

\section{VALIDATING GRAMMATICALITY JUDGMENT TESTS}

\section{Evidence from Two New Psycholinguistic Measures}

\author{
Payman Vafaee, Yuichi Suzuki, and Ilina Kachisnke
}

doi:http://dx.doi.org/ 10.1017/S0272263115000455, Published by Cambridge University Press, 8 January 2016

The authors of the above article (Vafaee et al., 2016) were listed in the wrong order. The correct order of authors is Payman Vafaee, Yuichi Suzuki, and Ilina Kachisnke. The publisher apologizes to the authors and readers for this error. The original article has been corrected to rectify this error.

\section{REFERENCE}

Vafaee, Payman, Suzuki, Y., and Kachisnke, I. Validating grammaticality judgment tests. Studies in Second Language Acquisition, doi:10.1017/S0272263115000455. 